\title{
An efficient synthesis of novel pyrano[2,3-d]- and furopyrano[2,3-d]pyrimidines via indium-catalyzed multi-component domino reaction
}

\author{
Dipak Prajapati ${ }^{*}$ and Mukut Gohain
}

\section{Full Research Paper}

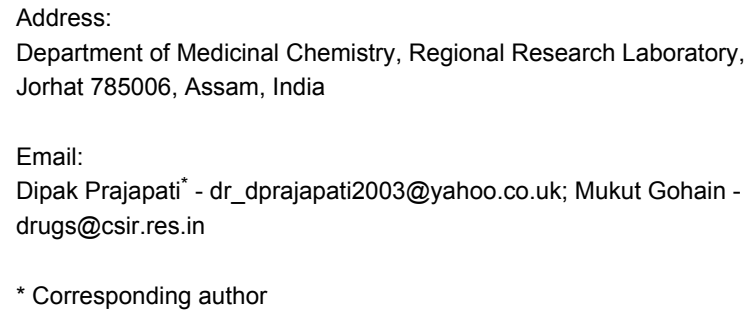

Beilstein Journal of Organic Chemistry 2006, 2, No. 11. doi:10.1186/1860-5397-2-11

Received: 17 February 2006

Accepted: 13 June 2006

Published: 13 June 2006

(c) 2006 Prajapati and Gohain; licensee Beilstein-Institut. License and terms: see end of document.

\begin{abstract}
Various novel pyrano [2,3- $d$ ]pyrimidines 5 and furopyrano [2,3- $d]$ pyrimidines 7 were synthesized in $80-99 \%$ yields via a multicomponent domino Knoevenagel/hetero-Diels-Alder reaction of 1,3-dimethyl barbituric acid with an aromatic aldehyde and ethyl vinyl ether/2,3-dihydrofuran in presence of $1 \mathrm{~mol} \%$ of indium(III) chloride. The reaction also proceeds in aqueous media without using any catalyst, but the yield is comparatively less (65-70\%).
\end{abstract}

\section{Introduction}

The emergence of indium(III) compounds as efficient Lewis acid catalysts presents new and exciting opportunities for organoindium chemistry. [1,2] It was found that the low reactivity of trivalent organoindium reagents can be increased by complex formation with organolithium compounds.[3] The tetra-organo-indates thus prepared are sufficiently reactive to take part in reactions at ambient temperature.[3] Moreover, indium metal[4] has been found to be an effective reducing agent and indium(III) halide or its complexes act[5] as an efficient, moisture compatable Lewis acid catalysts in Mukaiyama Aldol reactions, Friedel-Crafts acylations, [6] Pavarob reactions [7] and Diels-Alder reactions[8] in water. Since the work of Loh,[8] indium halide has also been shown to be an effective Lewis acid catalyst for various reactions in aqueous media. $[9,10]$ However, its use in the hetero Diels-Alder reaction of $\alpha, \beta$-ethylenic ketones and ethyl vinyl ether or 2,3- dihydrofuran has remained unexplored.[11] Herein, we report the first example of indium(III) chloride catalysed synthesis of fused pyrimidine derivatives via a multicomponent domino Knoevenagel hetero Diels-Alder reaction. The reaction proceeds efficiently at ambient temperature in excellent yields (Scheme 1).

Pyrimidine derivatives continue to be of great interest due to their wide range of biological activities.[12] Preparation of naturally occuring complex molecules containing a uracil ring pose significant synthetic challenges.[13] The development of clinically useful anticancer (5-fluorouracil)[14] and antiviral drugs (AZT, DDC, DDI, BVDU) [15-17] has renewed interest in the synthetic manipulation of uracils.[18] The synthesis of furopyrimidines has received little attention and only few procedures have been reported in the literature, [19-21] most of 

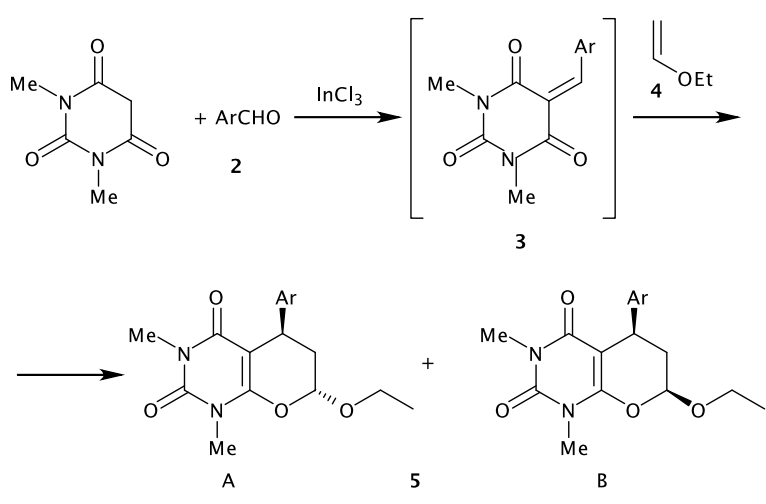

Scheme 1: Reagents and conditions: i) $1 \mathrm{~mol} \% \mathrm{InCl}_{3}$, acetonitrile:water (3:1)

which rely on multi-step reactions with yields being low. [22, 23] The furo [2,3- $d]$ pyrimidine derivatives act as useful sedatives, antihistamines, diuretics, muscle relaxants and antiulcer agents. Furthermore, pyrano $[2,3-d]$ pyrimidines also represent broad classes of annelated uracils. A number of compounds having these systems are synthesized with diverse pharmacological activity. [24,25] For the preparation of these complex molecules, there has been remarkable interest in the synthetic manipulations of uracils.[26] Also the synthetic exploitation of the nucleophilic double bond of uracil is an undeveloped field in view of a great variety of potential products. [27-29] Although a variety of routes for the synthesis of these compounds have been appeared in the literature, [30-33] the majority of them involve a number of steps, drastic conditions, long reaction time and low yields. Thus new routes for the synthesis of these molecules have attracted considerable attention in search for a rapid entry to these heterocycles and their diverse biological properties. In search of an efficient method and in continuation to our studies on uracil analogues [34,35], we have investigated a new, simple and efficient synthesis of novel fused pyrimidines based on inverse electron-demand Diels-Alder reaction using ethyl vinyl ether/dihydrofuran and $\alpha, \beta$-ethylenic ketones formed in situ as heterodienes in presence of $1 \mathrm{~mol} \%$ of indium(III) trichloride (Scheme 1). This type of cycloaddition using an amino aldehyde and a benzyl enol ether in presence of ethylene diammonium acetate and triethyl orthoformate has been reported earlier but this method has its own merits and limitations.[36]

\section{Results and Discussions}

On treatment of 1,3-dimethylbarbituric acid 1, 4-nitrobenzaldehyde 2a, ethyl vinyl ether $\mathbf{4}$ in acetonitrile:water (3:1) and in presence of $1 \mathrm{~mol} \%$ indium(III) trichloride, a one-pot threecomponent reaction proceeded spontaneously at room temper- ature. After completion and usual work-up the corresponding pyrano $[2,3-d]$ pyrimidine derivative 5a was obtained in $99 \%$ yields as a mixture of diastereomers. The structure of the compound was confirmed as $\mathbf{5 a}$ from the spectroscopic data and elemental analyses.

The NMR spectra showed the absence of the methylene proton of the 1,3-dimethylbarbituric acid and the presence of a proton at $\delta 5.46$ or at $\delta 5.25$. The configuration of the pyrano $[2,3-d]$ pyrimidine 5 was determined to be a mixture of cis and trans compounds, where the trans diastereomers are always predominant; in most cases they were separated by silica gel chromatography. For, example, elution of $\mathbf{5 a}$ with hexane/ethylacetate $(30: 10 \mathrm{v} / \mathrm{v})$ afforded first the trans diastereomer as a solid $\mathrm{mp}$ $170-72^{\circ} \mathrm{C}$ and then the minor cis diastereomer as a crystalline compound $\mathrm{mp} 153-55^{\circ} \mathrm{C}$ in the ratio $75: 25$. The NMR spectra of diastereomers A (trans) and B (cis) of compound 5a (for example) exhibited a resonance as a doublet of doublets attributable to the anomeric proton at $\delta=5.46(J=3.0$, and $6.3 \mathrm{~Hz})$ for the diastereomer $\mathrm{A}$ and at $\delta=5.25(J=2.1$ and $4.5 \mathrm{~Hz})$ for the diastereomer B, suggesting that the ethoxy substituent occupies a pseudoaxial position within the dihydropyran ring for the A diastereomer. The benzylic proton appeared as a triplet at $\delta=$ 4.15 and 4.19 for the diastereomer A and B with an apparent coupling constant $J=7.5$ and $6.6 \mathrm{~Hz}$ respectively. Analysis of the resonances of the equatorial and axial hydrogens located on the neighbouring methylene group of diastereomers A or B indicated, after spin decoupling, that the coupling constant are $J$ $=7.0$ and $6.1 \mathrm{~Hz}$ respectively for diastereomer A. The configuration of diastereomer A may therefore be assigned as trans and cis for the diasteromer B. The formation of these heterocycles 5 can be rationalized by initial formation of a conjugated electron-deficient heterodiene by standard Knoevenagel condensation of the aldehyde 2 with the 1,3-dimethylbarbituric acid,[37] which is highly activated due to the presence of the electron withdrawing group. It can, therefore, react with the ethyl vinyl ether at room temperature, to provide the cycloadduct 5 in a hetero-Diels-Alder reaction with inverse electron-demand. [38-40] Similarly, several aromatic aldehydes were reacted well to give the corresponding pyrano [2,3-d]pyrimidines in excellent yields ('see Supporting Information File 1'). However, the reaction did not proceed with aliphatic or heterocyclic aldehydes. The reaction is also effective when $1 \mathrm{~mol} \%$ of scandium or ytterbium triflate was used as catalyst but indium chloride gives better results (Table 1). In a control experiment, the reaction also proceeded without the use of any catalysts, but it yields the compound 5 in a (1:1) mixture of diastereomers in $65-70 \%$ yields (Table 1).

To further investigate the synthetic scope of this cycloaddition reaction, we reacted 2,3-dihydrofuran with 1,3-dimethylbarbit- 


\begin{tabular}{|c|c|c|c|c|c|c|}
\hline \multirow[t]{2}{*}{ Products } & \multirow[t]{2}{*}{$\mathrm{Ar}$} & \multirow[t]{2}{*}{ Catalyst } & \multirow{2}{*}{$\begin{array}{l}\text { Reaction time } \\
\text { (h) }\end{array}$} & \multirow{2}{*}{$\begin{array}{l}\text { Yield }(\%)^{\mathrm{a}} \\
\text { (cis:trans) }\end{array}$} & \multicolumn{2}{|c|}{$\mathrm{Mp}\left({ }^{\circ} \mathrm{C}\right)^{\mathrm{b}}$} \\
\hline & & & & & A (trans) & $\mathrm{B}$ (cis) \\
\hline $5 a$ & $4-\mathrm{NO}_{2}-\mathrm{C}_{6} \mathrm{H}_{4}-$ & $\mathrm{InCl}_{3}$ & 2.5 & $99(25: 75)$ & $170-72$ & $153-55$ \\
\hline $5 b$ & $\mathrm{C}_{6} \mathrm{H}_{5}$ & $\mathrm{InCl}_{3}$ & 3.5 & $95(30: 70)$ & $155-57$ & $148-50$ \\
\hline $5 c$ & $4-\mathrm{Cl}-\mathrm{C}_{6} \mathrm{H}_{4-}$ & $\mathrm{InCl}_{3}$ & 2.5 & $95(30: 70)$ & $174-75$ & $154-55$ \\
\hline $5 d$ & $4-\mathrm{CH}_{3}-\mathrm{C}_{6} \mathrm{H}_{4}$ & $\mathrm{InCl}_{3}$ & 3.5 & $90(30: 70)$ & $165-68$ & $146-48$ \\
\hline $5 e$ & $4-\mathrm{CH}_{3} \mathrm{O}-\mathrm{C}_{6} \mathrm{H}_{4}$ & $\mathrm{InCl}_{3}$ & 3.5 & $90(30: 70)$ & 198-99 & $189-90$ \\
\hline $5 a$ & $4-\mathrm{NO}_{2}-\mathrm{C}_{6} \mathrm{H}_{4}-$ & $\mathrm{Sc}(\mathrm{OTf})_{3}$ & 3.0 & $85(45: 55)$ & $168-72$ & $153-55$ \\
\hline $5 b$ & $\mathrm{C}_{6} \mathrm{H}_{5}$ & $\mathrm{Sc}(\mathrm{OTf})_{3}$ & 3.5 & $80(35: 65)$ & $155-57$ & $148-50$ \\
\hline $5 c$ & $4-\mathrm{Cl}-\mathrm{C}_{6} \mathrm{H}_{4^{-}}$ & $\mathrm{Sc}(\mathrm{OTf})_{3}$ & 3.0 & $80(45: 55)$ & $174-75$ & $154-55$ \\
\hline $5 d$ & $4-\mathrm{CH}_{3}-\mathrm{C}_{6} \mathrm{H}_{4}$ & $\mathrm{Sc}(\mathrm{OTf})_{3}$ & 3.5 & $80(45: 55)$ & $165-68$ & $146-48$ \\
\hline $5 e$ & $4-\mathrm{CH}_{3} \mathrm{O}-\mathrm{C}_{6} \mathrm{H}_{4}$ & $\mathrm{Sc}(\mathrm{OTf})_{3}$ & 3.5 & $82(25: 75)$ & 198-99 & $189-90$ \\
\hline $5 a$ & $4-\mathrm{NO}_{2}-\mathrm{C}_{6} \mathrm{H}_{4}^{-}$ & -- & 4.0 & $70(50: 50)$ & $168-72$ & $153-55$ \\
\hline $5 b$ & $\mathrm{C}_{6} \mathrm{H}_{5}$ & -- & 4.5 & 65 (50:50) & $155-57$ & $148-50$ \\
\hline $5 d$ & $4-\mathrm{CH}_{3}-\mathrm{C}_{6} \mathrm{H}_{4}$ & -- & 4.5 & $70(50: 50)$ & $165-66$ & $146-48$ \\
\hline $7 a$ & $4-\mathrm{NO}_{2}-\mathrm{C}_{6} \mathrm{H}_{4^{-}}$ & $\mathrm{InCl}_{3}$ & 8.0 & 80 & $145-47$ & -- \\
\hline $7 b$ & $\mathrm{C}_{6} \mathrm{H}_{5}$ & $\mathrm{InCl}_{3}$ & 10 & 85 & $156-57$ & -- \\
\hline $7 c$ & $4-\mathrm{Cl}-\mathrm{C}_{6} \mathrm{H}_{4-}$ & $\mathrm{InCl}_{3}$ & 8.0 & 90 & $178-80$ & -- \\
\hline $7 d$ & $4-\mathrm{CH}_{3}-\mathrm{C}_{6} \mathrm{H}_{4}$ & $\mathrm{InCl}_{3}$ & 8.0 & 80 & $156-57$ & -- \\
\hline $7 e$ & $4-\mathrm{CH}_{3} \mathrm{O}-\mathrm{C}_{6} \mathrm{H}_{4}$ & $\mathrm{InCl}_{3}$ & 10 & 82 & $153-54$ & -- \\
\hline
\end{tabular}

alsolated yields. ${ }^{\mathrm{b}}$ All products were characterized by ${ }^{1} \mathrm{H}$ NMR IR and mass spectra.

uric acid and an aromatic aldehyde at room temperature in presence of $1 \mathrm{~mol} \%$ of indium(III) trichloride under similar conditions. The reaction after usual work-up gave the corresponding furopyrano $[2,3-d]$ pyrimidine 7 in excellent yields. Knoevenagel condensation of the aromatic aldehyde with 1,3-dimethylbarbuturic acid occurs first with the formation of an electrondeficient, sterically fixed 1-oxo-1,3-butadiene 3 which then reacts with 2,3-dihydrofuran in a Diels-Alder reaction with inverse-electron demand[13] to afford furopyrano [2,3-d] pyrimidines 7 (Scheme 2). The structure of the compound 7 thus obtained was assigned on the basis of its elemental and spectral analyses ('see Supporting Information File 2 '). The ${ }^{1} \mathrm{H}$ NMR shows the absence of methylene proton of barbutric acid and the presence of a proton at $\delta 5.75$ and two methyl groups of the cycloadducts 7 at $\delta=3.25$ (s, 3H, NMe), 3.48 (s, 3H, NMe) $\mathrm{ppm}$. To generalize this reaction we reacted various substituted aromatic aldehydes and isolated the corresponding furopyrano $[2,3-d]$ pyrimidines in $80-90 \%$ yields. In all cases the reactions proceeded smoothly at ambient temperature with high selectivity. The tetrahydrofuran ring is cis fused as depicted by the coupling constant of the protons at $\delta 5.75 \mathrm{~J}=6 \mathrm{~Hz}$ and $\delta$ $4.48 J=5.4 \mathrm{~Hz}$. Several examples illustrating this novel and rapid procedure for the synthesis of fused pyrimidines are summarized in the Table 1. Remarkably, this Diels-Alder reaction was also proceeded similarly when 5-benzylidene barbituric acid was employed directly with 2,3-dihydrofuran in presence of $1 \mathrm{~mol} \%$ of indium(III) chloride. The corresponding furopyrano $[2,3-d]$ pyrimidine derivatives 7 were obtained in almost comparable yields. The structure of all the products thus obtained were characterized by elemental and spectral analyses.

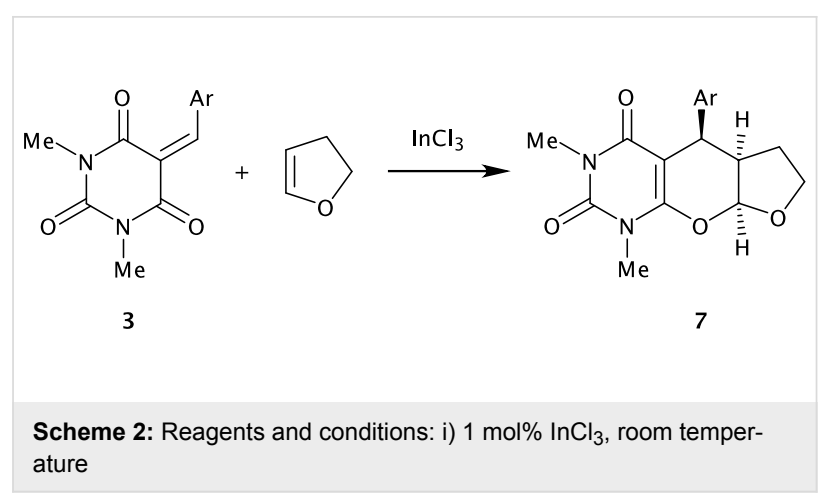

\section{Conclusion}

In conclusion, we have shown that the multicomponent domino Knoevenagel condensation/hetero-Diels-Alder reaction of aromatic aldehydes with 1,3-dimethylbarbituric acid and ethyl vinyl ether or dihydrofuran catalysed by $\mathrm{InCl}_{3}$ is a powerful and efficient method for the synthesis of novel fused pyrimidines of biological significance. In addition to its efficiency, simplicity and milder reaction conditions this method provides excellent yields of products with selectivity, which makes it a useful process for the synthesis of cis-fused furopyrano [2,3-d] pyrimidines and pyrano $[2,3-d]$ pyrimidines. 


\section{Supporting Information}

\section{Supporting Information File 1}

contains full experimental data

[http://www.beilstein-journals.org/bjoc/content/

supplementary/1860-5397-2-11-S1.doc]

\section{Supporting Information File 2}

contains supplementary information of compounds $5 \& 7$.

[http://www.beilstein-journals.org/bjoc/content/

supplementary/1860-5397-2-11-S2.doc]

\section{Acknowledgments}

We thank the Department of Science \& Technology (DST), New Delhi for financial assistance to this work. One of us (MG) thanks CSIR, New Delhi for the award of a Senior Research Fellowship to him.

\section{References}

1. Araki, S.; Jin, S. J.; Butsugan, Y. J. Chem. Soc., Perkin Trans. 1 1995, 549. doi:10.1039/p19950000549

2. Loh, T. P.; Li, X. R. J. Chem. Soc., Chem. Commun. 1996, 1929.

3. Jin, S. J.; Araki, S.; Butsugan, Y. Bull. Chem. Soc. Jpn. 1993, 66, 1528. doi:10.1246/bcsj. 66.1528

4. Li, C. J.; Chan, T. K. Tetrahedron 1999, 55, 11149. doi:10.1016/S00404020(99)00641-9

A review on indium metal.

5. Loh, T. P.; Pai, J.; Cao, G. Q. J. Chem. Soc., Chem. Commun. 1996, 1819.

6. Li, C. J.; Chen, D. L.; Lu, Y. Q.; Daberman, J. X.; Mague, J. T. J. Am. Chem. Soc. 1996, 118, 4216. doi:10.1021/ja960489p

7. Zhang, J.; Li, C.-J. J. Org. Chem. 2002, 67, 3969. doi:10.1021/ jo020131d

8. Loh, T. P.; Pai, J.; Lin, M. J. Chem. Soc., Chem. Commun. 1996, 2315.

9. Chan, T. H. Pure Appl. Chem. 1996, 68, 919. doi:10.1351/ pac199668040919

A review on synthetic applications of indium and indium reagents.

10. Chauhan, K. K.; Frost, C. G. J. Chem. Soc., Perkin Trans. 1 2000, 3015. doi:10.1039/a906657h

11. Ranu, B. C. Eur. J. Org. Chem. 2000, 2347. A review.

12. Jones, A. S.; Swgers, J. R.; Walker, R. T.; Clercq, E. D. J. Med. Chem. 1988, 31, 268. doi:10.1021/jm00396a043

13. Brown, J. D. In Comprehensive Heterocyclic Chemistry; Katritzky, A. R.; Rees, C. W., Eds.; Pergamon Press: Oxford, 1984; Vol. 3, pp 57 ff.

14. Heidelberger, C.; Arafield, F. J. Cancer Res. 1963, 23, 1226. Chem. Abstr. 1964, 60, 2197.

15. Clercq, E. D. J. Med. Chem. 1986, 29, 1561. doi:10.1021/jm00159a001

16. Baba, M.; Pauvels, R.; Herdwig, P.; Clercq, E. D.; Desmyster, J.; Vandepulfe, M. Biochem. Biophys. Res. Commun. 1987, 142, 128. doi:10.1016/0006-291X(87)90460-8

17. Clercq, E. D. Anticancer Res. 1986, 6, 549.

18. Hirota, K.; Kubo, K.; Sajiki, H.; Kitade, Y.; Sako, M.; Maki, Y. J. Org Chem. 1997, 62, 2999. doi:10.1021/jo962200s
19. Qian, C.-Y.; Nishino, H.; Kurosawa, K.; Korp, J. D. J. Org. Chem. 1993, 58, 4448. doi:10.1021/jo00068a046

20. Kawahara, N.; Nakajima, T.; Itoh, T.; Ogura, H. Heterocycles 1984, 22, 2217.

21. Kawahara, N.; Nakajima, T.; Itoh, T.; Ogura, H. Chem. Pharm. Bull. 1985, 33, 4740.

22. Figueroa-Villar, J. D.; Carneiro, C. L.; Cruz, E. R. Heterocycles 1992, $34,891$.

23. Kobayashi, K.; Tanaka, H.; Tanaka, K.; Yoneda, K.; Morikawa, O.; Konishi, H. Synth. Commun. 2000, 30, 4277.

24. Anderson, G. L.; Shim, J. L.; Brown, A. D. J. Org. Chem. 1976, 41, 1095. doi:10.1021/jo00869a003

25. Grivaky, E. M.; Lee, S.; Siyal, C. W.; Duch, D. S.; Nichol, C. A. J. Med. Chem. 1980, 23, 327. doi:10.1021/jm00177a025

26. Hirota, K.; Kitade, Y.; Senda, S.; Halat, M. J.; Watanabe, A. K.; Fox, J. J. J. Org. Chem. 1981, 46, 846. doi:10.1021/jo00318a004

27. Taylor, E. C.; Sawinski, F. J. Org. Chem. 1974, 39, 907. doi:10.1021/ jo00921a010 Wamhoff H, Winfried S: J Org Chem 1986, 51: 2787.

28. Wamhoff, H.; Winfried, S. J. Org. Chem. 1986, 51, 2787. doi:10.1021/ jo00364a032

29. Sasaki, T.; Minamoto, T.; Suzuki, T.; Suguira, T. J. Am. Chem. Soc. 1978, 100, 2248. doi:10.1021/ja00475a055

30. Ahluwalia, V. K.; Kumar, R.; Khurana, K.; Bhatia, R. Tetrahedron 1990, 46, 1963. doi:10.1016/S0040-4020(01)90530-7

31. Ahluwalia, V. K.; Aggarwal, R.; Alauddin, M.; Gill, G.; Khanduri, C. H. Heterocycles 1990, 31, 129.

32. Hirota, K.; Kuki, H.; Maki, Y. Heterocycles 1994, 37, 563.

33. Srivastava, P.; Saxena, A. S.; Ram, V. J. Synthesis 2000, 541 doi:10.1055/s-2000-6371

34. Prajapati, D.; Thakur, A. J. Tetrahedron Lett. 2005, 43, 1433. doi:10.1016/j.tetlet.2005.01.047 And references cited therein.

35. Thakur, A. J.; Saikia, P.; Prajapati, D.; Sandhu, J. S. Synlett 2001, 1299. doi:10.1055/s-2001-16036

36. Tietze, L. F.; Evers, H.; Topken, E. Angew. Chem., Int. Ed. 2001, 40, 903. doi:10.1002/1521-3773(20010302)40:5<903::AIDANIE903>3.0.CO;2-7

37. Tietze, L. F.; Beifuss, U. In Comprehensive Organic Synthesis; Trost B. M.; Fleming, I.; Heathcock, C., Eds.; Pergamon Press: Oxford, 1991; Vol. 2, pp $341 \mathrm{ff}$.

38. Tietze, L. F.; Beifuss, U. Angew. Chem. 1993, 105, 137. doi:10.1002/ ange.19931050204 Angew. Chem., Int. Ed. 1993, 32, 131.

39. Tietze, L. F. Chem. Rev. 1996, 96, 115. doi:10.1021/cr950027e

40. Tietze, L. F.; Heissler, H.; Fennen, J.; Brumby, T.; Brand, S.; Schulz, G. J. Org. Chem. 1994, 59, 182. doi:10.1021/j000080a030 


\section{License and Terms}

This is an Open Access article under the terms of the Creative Commons Attribution License

(http://creativecommons.org/licenses/by/2.0), which permits unrestricted use, distribution, and reproduction in any medium, provided the original work is properly cited.

The license is subject to the Beilstein Journal of Organic Chemistry terms and conditions:

(http://www.beilstein-journals.org/bjoc)

The definitive version of this article is the electronic one which can be found at:

doi:10.1186/1860-5397-2-11 